\title{
Is Rotavirus Immunization Safe in Infants Born to Mothers Treated with Immunosuppressive Drugs for Inflammatory Bowel Disease During Pregnancy?
}

\author{
R.Christina Smith, $M D^{1}$, Meera N. Patel ${ }^{2}$, Richard Sigmon, $M D^{3}$, Niraj C. Patel, $M D, M S^{1}$ \\ 'Division of Pediatrics, Division of Pediatric Infectious Disease and Immunology, Atrium Health, Charlotte, NC, USA \\ ${ }^{2}$ North Carolina School of Science and Math, 3Department of Internal Medicine, Division of Gastroenterology, Atrium Health, Charlotte, NC, USA
}

Article Info

\section{Article Notes}

Received: October 04, 2020

Accepted: December 16, 2020

\section{${ }^{*}$ Correspondence:}

${ }^{*}$ Dr. Niraj C. Patel MD, MS, Chief Pediatric Infectious Disease and Immunology, Director, Charlotte Immunodeficiency Center Levine Children's Hospital Atrium Health, Charlotte, NC, USA; Email: Niraj.Patel@atriumhealth.org.

(c) 2020 Patel NC. This article is distributed under the terms of the Creative Commons Attribution 4.0 International License.

\section{Keywords}

Biologic

Infliximab

Rotavirus

Vaccine

\section{ABSTRACT}

The licensed rotavirus vaccines are live attenuated and are a component of the routine U.S. childhood immunization schedule. Live vaccines administered to infants of mothers who received biologic response modifiers (BRM) during pregnancy can potentially cause serious vaccine-associated disease. The Advisory Committee on Immunization Practices (ACIP) recommends infants born to women who received BRM during pregnancy avoid live viral vaccines during the first year of life. There is a paucity of information regarding adverse events following inadvertent administration of live viral vaccines in these infants. We report three infants, born to mothers receiving infliximab during pregnancy, who tolerated multiple doses of rotavirus vaccine. Live viral vaccines may be safe in infants who were exposed to BRM in utero. Further studies are needed to support this observation, as this could affect current ACIP recommendations.

\section{Abbreviations}

ACIP, Advisory Committee on Immunization Practices

BCT, bacille Calmette-Guerin

BRM, biologic response modifiers

IBD, inflammatory bowel disease

TNF- $\alpha$, tumor necrosis factor alpha

\section{Introduction}

Tumor necrosis factor alpha (TNF- $\alpha$ ) inhibitors, a subsetof biologic response modifiers (BRM), are commonly used as first-line agents to treat inflammatory bowel disease (IBD) (e.g. Crohn's disease). Known for their immunosuppressive effects, TNF- $\alpha$ inhibitors can cross the placenta into fetal circulation and have demonstrated variable clearance in infants, including up to 12 months after delivery ${ }^{1,2}$. Infant death from disseminated mycobacterial infection after vaccination with live attenuated bacille Calmette-Guerin (BCG) in an infant whose mother received antepartum infliximab has been described $^{3}$. Safety concerns associated with the administration of live viral vaccines in severely immunocompromised patients have been documented ${ }^{4}$.

Rotavirus can cause severe diarrheal illness in young children and is still considered one of the most common causes of diarrheal disease in infants worldwide ${ }^{5}$. The licensed rotavirus 
vaccines contain live attenuated viruses and are a part of the standard childhood immunization schedule. One of two rotavirus vaccine series is administered orally: Rotateq ${ }^{\circledR}$ is a pentavalent vaccine given orally as a three-dose series at 2, 4, and 6 months, and Rotarix ${ }^{\circledR}$ is monovalent vaccine given orally as a two-dose series at 2 and 4 months of age ${ }^{6-10}$. The Advisory Committee on Immunization Practices (ACIP) and Red Book ${ }^{11}$ recently recommended avoidance of live virus vaccines in the first year of life in infants born to mothers taking BRM due to the theoretical risk of disseminated infant infection. We sought to explore the safety of inadvertent administration of rotavirus vaccine in infants exposed to TNF- $\alpha$ inhibitors in utero.

\section{Methods}

A retrospective chart review was conducted of three children exposed to infliximab in utero who received either 2 or 3 doses of the rotavirus vaccination series. Primary outcomes including safety and efficacy of rotavirus vaccination were studied. Information was collated on: characteristics of the mothers, timing of biologic infusions, other medications or immunomodulators being taken for disease control, patient characteristics, timing of rotavirus administration, adverse reactions to rotavirus, and other chronic health problems was gathered. This study was approved by the Institutional Review Board.

\section{Results}

\section{Patient \#1}

The mother had received regular infliximab infusions throughout pregnancy to achieve control of her IBD (Mother 1, Table 1). Per her infusion schedule, she received infliximab at 3, 9, 15, 21, and 27 weeks of the pregnancy. A female infant (Infant 1, Table 2), born at 33 weeks estimated gestational age had an uncomplicated neonatal intensive care stay following birth primarily for feeding issues. Apart from being born prematurely, this infant has no known chronic medical conditions and her feeding issues were resolved at the end of her NICU stay. The infant received rotavirus vaccination (Rotarix ${ }^{\circledR}$ ) at 2 and 4 months of age. The child's chart was monitored for sick visits, urgent care visits, hospitalizations, and ED visits in the first year of life; no serious or minor adverse events were reported. No diarrheal or febrile illness were reported following vaccine administration and the child avoided both emergency care and hospitalizations in the first year of life.

\section{Patient \#2}

The second mother was suffering from Crohn's disease (Mother 2, Table 1), she received infliximab infusions at $6,12,18,24,30$ and 35 weeks of pregnancy. A male infant (Infant 2, Table 2) was born at term and had no health-related problems after birth; he does not have any known chronic medical conditions. He received rotavirus vaccination (Rotateq ${ }^{\circledR}$ ) at 2, 4 and 6 months of age. The child's chart was monitored for sick visits, urgent care visits, hospitalizations, and ED visits in the first year of life; no serious or minor adverse events were reported. No diarrheal or febrile illness were reported following vaccine administration and the child avoided both emergency care and hospitalizations in the first year of life.

\section{Patient \#3}

The mother was suffering from ulcerative colitis (Mother 2, Table 1) and received infliximab infusions at approximately $8,17,25$, and 33 weeks gestation. Notably, this mother received half the recommended dose of her infliximab infusion per patient preference. The third female infant (Infant 3, Table 2) was born full term. This infant has no known chronic medical conditions documented as of 1 year of life. The infant incidentally received 2 doses of Rotateq ${ }^{\circledR}$ at her 2-and 6-month wellchild visits. The child's chart was monitored for sick visits, urgent care visits, hospitalizations, and ED visits in the first year of life; no serious or minor adverse events were reported. No diarrheal or febrile illness were reported following vaccine administration and the child avoided both emergency care and hospitalizations in the first year of life.

\begin{tabular}{|c|c|c|c|}
\hline & Mother 1 & Mother 2 & Mother 3 \\
\hline Diagnosis & Crohn's Disease & Crohn's Disease & Ulcerative Colitis \\
\hline Treatment & $\begin{array}{c}\text { Infliximab infusions } \\
\text { every } 6 \text { weeks }\end{array}$ & $\begin{array}{c}\text { Infliximab infusions } \\
\text { every } 6 \text { weeks }\end{array}$ & $\begin{array}{c}\text { Infliximab infusions every } 8 \text { weeks at half the recommended } \\
\text { dose }\end{array}$ \\
\hline Co-morbid Conditions & None & None & $\begin{array}{l}\text { Hypothyroidism (on levothyroxine), type II autoimmune } \\
\text { pancreatitis, hypercoagulable state (on enoxaparin) and } \\
\text { obesity }\end{array}$ \\
\hline $\begin{array}{l}\text { Immunomodulators in addition to } \\
\text { biologic therapy }\end{array}$ & None & None & None \\
\hline $\begin{array}{l}\text { Other medications in addition to } \\
\text { infliximab }\end{array}$ & Mesalamine & None & None \\
\hline Last infliximab infusion prior to delivery & 27 weeks EGA & 35 weeks EGA & 33 weeks EGA \\
\hline
\end{tabular}

EGA, estimated gestational age 
Table 2: Characteristics of Infants Exposed in Utero to Tumor Necrosis Factor Alpha Inhibitors

\begin{tabular}{|c|c|c|c|}
\hline & Infant 1 & Infant 2 & Infant 3 \\
\hline Gender & Female & Male & Female \\
\hline EGA at birth & 33 weeks & 39 weeks & 39 weeks \\
\hline Birth/Perinatal Complications & $\begin{array}{l}\text { Brief uncomplicated NICU stay due } \\
\text { to preterm birth }\end{array}$ & None & None \\
\hline Timing of rotavirus vaccination & 2 months and 4 months (Rotarix ${ }^{\circledR}$ ) & 2 months, 4 months and 6 months (Rotateq ${ }^{\circledR}$ ) & 2 and 6 months (Rotateq ${ }^{\circledR}$ ) \\
\hline Adverse reactions & None & None & None \\
\hline Vaccine associated disease & None & None & None \\
\hline Comorbid conditions & Born premature & None & None \\
\hline Current Age & 9 years & 5 years & 18 months \\
\hline
\end{tabular}

EGA = estimated gestation age; NICU=Neonatal Intensive Care Unit

\section{Discussion}

We report 3 infants whose mothers had received infliximab during pregnancy as summarized in Table 1. All 3 infants received 2 or 3 doses of live rotavirus vaccine without reported adverse events. Maternal and infant characteristics are discussed in tables 1 and 2, respectively.

Rotavirus vaccination is important in preventing rotavirus in infants and is part of the standard vaccine schedule for infants within the first year of life. According to the ACIP, the first dose of the vaccine must be given between 6 weeks and 14 weeks and 6 months of life. The minimum time in between doses of the vaccine is 1 month, and the last dose of the vaccine must be given within the first 6 months of life. If a child is unable to receive any or all doses of the rotavirus vaccine according to these parameters, catch-up vaccination should not be pursued.

It has been reported that an infant whose mother received a TNF- $\alpha$ inhibitor during pregnancy died related to complications from administration of the BCG vaccine ${ }^{3}$. Furthermore, serum levels of TNF- $\alpha$ inhibitors have been detected in infants up to 1 year of age whose mothers received biologics during pregnancy ${ }^{2}$. This has led the ACIP to recommend current avoidance of live viral vaccines, including rotavirus, in infants up to 1 year of age whose mothers received BRM during pregnancy. Previous reports of safe administration of rotavirus vaccine to such infants have been documented ${ }^{12}$. In the current study 3 infants tolerated receipt of the rotavirus vaccine.

While no serious adverse outcomes were reported in our patients, the three infants in our case series received doses of the rotavirus vaccine inadvertently. It is worth exploring how these infants received the rotavirus vaccination in spite of guidelines to withhold live vaccines in these patients. This preventable adverse event may be linked to barriers of communication between the adult GI physicians caring for the mothers and the pediatricians caring for the infants. Compounding this issue, pediatric providers may not be familiar with the potential side effects of infliximab as it is not a commonly prescribed drug in the general pediatric population. The pediatricians may not have access to the mother's full records and there are multiple well checks to inadvertently administer the vaccine increasing the likelihood of an error causing administration of the rotavirus vaccine. Notably, one of the infant's parents asked multiple times at each visit if a live virus vaccine was being administered; this infant was still given two doses of the rotavirus vaccine at two separate visits. Without appropriate education and communication between providers and parents, exposure to potential adverse events will continue to occur. One potential mechanism to prevent inadvertent vaccine administration would entail documentation of a contraindication of live rotavirus vaccine in the patient's electronic medical record at the newborn visit.

Interestingly, all 3 of our patients tolerated most or all of the rotavirus vaccine series. This may be related to a dampened immunosuppressive effect on the infant from maternal administration of infliximab during pregnancy. However, another possibility is that the infants are able to produce an adequate $B$ cell response in spite of the presence of infliximab. TNF- $\alpha$ inhibitors act through a variety of mechanisms to quiet the immune system. Although TNF- $\alpha$ inhibitors are associated with increased risk of infection, many of these infections are only effectively eliminated through a robust TNF- $\alpha$ dependent and $\mathrm{T}$ cell-mediated response ${ }^{13}$. For instance, granuloma formation in mycobacterial infection is critically dependent on TNF signaling and activation of T-cells to stimulate macrophages ${ }^{14}$. It is thought that humoral immunity and the production of IgA are sufficient in developing immunity from rotavirus ${ }^{15,16}$. Although the $\mathrm{T}$ cell-mediated co-stimulatory signal would likely be attenuated in the presence of infliximab, it is possible these infants are producing sufficient IgA to achieve a protective effect against rotavirus antigens without the $\mathrm{T}$ cell response. This would lead to not only immunity but prevention of serious infection when exposed to live attenuated virus vaccine. In support of this theory, it has been well documented that some patient populations with congenital T-cell deficiencies tolerate vaccination with live viral vaccines ${ }^{17}$. Rotavirus vaccination is also not contraindicated in infants born to 
HIV-1 positive mothers ${ }^{18,19}$. This study is limited by the low number of reported subjects. This study is further limited by lack of data on rotavirus shedding in the stool following administration of the vaccine series. Serum infliximab levels were not measured in this study and knowledge of the immune status of infants at the time of rotavirus administration is unknown. There is a paucity of data regarding the immune status of these infants; prospective research is needed to further evaluate the immune status of these infants prior to rotavirus administration.

\section{Conclusions}

Administration of live rotavirus vaccine is currently contraindicated for routine childhood immunization in infants exposed to BRM in utero. This study suggests that some infants who were exposed to TNF- $\alpha$ inhibitors in utero may have successfully reacted to the live viral vaccines such as rotavirus. More data is needed to understand whether revisions to current routine immunization guidelines are needed. In the future, prospective research might include obtaining IgA levels in infants prior to administration of rotavirus vaccine.

\section{References}

1. Shi HY, Ng SC. The state of the art on treatment of Crohn's disease. J Gastroenterol. 2018;53(9), 989-998.

2. Julsgaard M, Christensen LA, Gibson PR, et al. Concentrations of adalimumab and infliximab in mothers and newborns, and effects on infection. Gastroenterol. 2016;151(1), 110-119.

3. Cheent K, Nolan J, Sohail S, et al. Case Report: Fatal case of disseminated BCG infection in an infant born to a mother taking infliximab for Crohn's Disease J Crohns Colitis. 2010;4(5), 603-605.

4. Patel NC, Hertel PM, Estes MK, et al. Vaccine-acquired rotavirus in infants with severe combined immunodeficiency. N Engl J Med. 2010;362(4), 314-319.

5. Chiejina M, Samant H. Viral diarrhea. StatPearls. 2020. Jan-. Available from: https://www.ncbi.nlm.nih.gov/books/NBK470525/

6. Jonesteller C, Burnett E, Yen C, et al. Effectiveness of rotavirus vaccination: a systemic review of the first decade of global postlicensure data, 2006-20016. Clin Infect Dis. 2017;65(5),8480-850.
7. Burnett E, Jonesteller C, Tate JE, et al. Global impact of rotavirus vaccination on childhood hospitalizations and mortality from diarrhea. J Infect Dis. 2017;215(11),1666-1672.

8. Burke RM, Tate JE, Kirkwood CD, et al. Current and new rotavirus vaccines. Curr Opin Infect Dis. 2019;32(5), 435-444.

9. Burnett E, Parashar U, Tate J. Lancet Glob Health. 2020;8(9), e1195-e1202.

10. Soares-Weiser K, Bergman $H$, Henschke $N$, et al. Vaccines for preventing rotavirus diarrhoea: vaccines in use. Cochrane Database Syst Rev. 2019;2019(10):CD008521.

11. American Academy of Pediatrics. Rotavirus Infections. In: Kimberlin DW, Brady MT, et al. eds. Red Book: 2018 Report of the Committee on Infectious Diseases. American Academy of Pediatrics. 2018; 700704.

12. Beaulieu DB, Ananthakrishnan AN, Martin C, et al. Use of biologic therapy by pregnant women with inflammatory bowel disease does not affect infant response to vaccines. Clin Gastroenterol Hepatol. 2018; 16:1, 99-105.

13. Aberra FN, Lichtenstein GR. Methods to avoid infections in patients with inflammatory bowel disease. Inflamm Bowel Dis. 2005; 11:7, 685-695.

14. Pagán AJ, Ramakrishnan L. Immunity and immunopathology in the tuberculous granuloma. Cold Spring Harb Perspect Med. 2014;5(9):a018499.

15. Davignon JL, Rauwel B, Degboe Y, et al. Modulation of T-cell responses by anti-tumor necrosis factor treatments in rheumatoid arthritis: a review. Arthritis Res Ther. 2018;20(1):229.

16. Angel J, Steele AD, Franco MA. Correlates of protection for rotavirus vaccines: possible alternative trial endpoints, opportunities, and challenges. Hum Vaccin Immunother. 2014;10(12),3659-3671.

17. Miranda M, Martins AT, Carvalho $S$, et al. Live vaccine in children with DiGeorge/22q11.2 deletion syndrome. Acta Med Port. 2019;32(78);514-519.

18. Adetokunboh 00, Ndwandwe D, Awotiwon A, et al. Vaccination among HIV-infected, HIV-exposed uninfected and HIV-uninfected children: a systematic review and meta-analysis of evidence related to vaccine efficacy and effectiveness. Hum Vaccin Immunther. 2019;15(11),2578-2589.

19. Bamford A, Manno EC, Mellado MJ, et al. Immunisation practices in centres caring for children with perinatally acquired HIV: A call for harmonisation. Vaccine. 2016;34(46),5587-5594. 